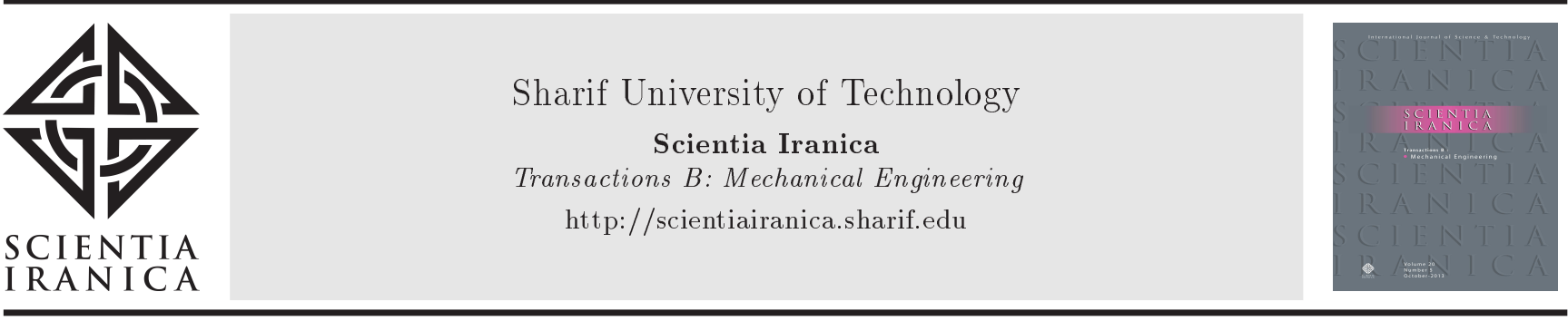

\title{
Theoretical and experimental investigation of design parameter effects on the slip phenomenon and performance of a centrifugal compressor
}

\author{
S. Rajabpour, A. Hajilouy Benisi*, and M.T. Manzari \\ School of Mechanical Engineering, Sharif University of Technology, Tehran, P.O. Box 11155/8639, Iran.
}

Received 1 March 2019; received in revised form 28 August 2019; accepted 3 March 2020

KEYWORDS
Centrifugal
compressor;
Slip factor;
CFD;
Experimental test.

\section{Introduction}

Slip factor is a significant performance parameter for centrifugal compressors. It determines the capability of a machine to transfer energy to the fluid flow [1]. The pressure ratio of centrifugal compressors is a function of efficiency and slip factor [2]. Therefore, obtaining accurate information about the slip phenomenon is essential for an efficient design. Different elements of the centrifugal compressor are usually individually

*. Corresponding author. Tel.: +982166165512 E-mail address: hajilouy@sharif.ir (A. Hajilouy Benisi)

doi: $10.24200 /$ sci. 2020.53042 .3040 designed and the slip factor is a measure of matching these components [3,4]. The fluid entering the impeller is considered irrotational. In a rotating frame of reference, a relative eddy rotating around the opposite direction of the impeller is required to maintain an irrotational flow in the absolute frame. The blades do not direct the flow correctly due to the presence of this relative eddy and this is the basis of the slip [5].

Many efforts have been made to develop a simple equation to predict the slip factor. However, there are only a few published papers in the literature that have considered the effects of design parameters on the slip factor of centrifugal compressors. Previous researchers have managed to derive a simple equation to predict the slip factor based on experimental data. Stodola 
suggested Eq. (1) for slip factor $(\sigma)$ in centrifugal impellers as a function of blade exit angle $\left(\beta_{2}\right)$ and the number of blades $(Z)[6]$ :

$$
\sigma=1-\left(\frac{\pi \sin \left(\beta_{2}\right)}{Z}\right) \quad 60<\beta_{2}<70 .
$$

The slip factor in this relation is defined in the following:

$$
\sigma=\frac{C_{u 2}^{\prime}}{u_{2}}+\frac{\varphi_{2}}{\tan \left(\beta_{2}\right)},
$$

where $C_{u_{2}}^{\prime}, u_{2}$, and $\varphi_{2}$ are the tangential component of flow velocity, blade speed, and flow factor at the impeller exit, respectively.

Busemann (1928) revised some of previous equations and analytically solved a two-dimensional inviscid flow field around the impeller [4]. He developed a set of curves to predict the slip factor as a function of several parameters such as the number of blades, exit angle of blades, and radius ratio.

Wislicenus (1947) showed that the accuracy of equations depended on the working condition of the compressor [7]. Studies on several radial impellers [8] led Stanitz to one of the most popular equations for the slip factor in 1952 [9]:

$$
\sigma=1-\frac{0.63 \pi}{Z}
$$

At exit angles lower than 30 degrees with the number of blades larger than 8 , the results of the slip factor obtained using Eqs. (1) and (3) were close to Busemann curves.

Wiesner (1967) developed an equation for the slip factor, as shown in the following [4]:

$$
\sigma=1-\frac{\sqrt{\cos (\beta)}}{Z^{0.7}}
$$

Simple equations were developed for the slip factor in centrifugal compressors by including more parameters and evaluating the accuracy of these equations with experimental data $[3,10]$. Such studies have only focused on the slip factor rather than the slip phenomenon. Researchers have also simplified the flow field by assuming simple blade curves or neglecting the effects of other design parameters [3].

Whitfield and Baines (1990) showed that the available equations for slip factor were not applicable to an optimum design since they did not include enough parameters [2]. Then, Whitfield presented an analytical method based on the jet/wake model [11]. Von Backstrorm (2006) developed an equation for the slip factor of a simple impeller as follows [12]:

$$
\sigma=1-\frac{1}{1+\left(2+3 \cos (\beta) \frac{(1-R R) Z}{2 \pi \cos (\beta)}\right)},
$$

where " $R R$ " is the impeller inner-to-outer radius ratio.
He expanded this analytical work by involving parameters such as radius ratio and blade shape and solidity in the prediction of the slip factor [13]. The major drawback of these analytical works is that they are limited to specific simple geometries and simplifications [14].

A majority of recent studies on the slip phenomenon in centrifugal impellers have investigated pumps $[15,16]$ and considered some parameters such as flow rate, rotational speed, impeller exit angle, radius ratio, and blade geometry to evaluate the slip factor $[17,18]$. Ghaderi et al. (2015) used a neural network method to predict the slip factor obtained from a set of experimental data. This method accounts for the nonlinearity of the relationship between parameters and the slip factor [19].

Hung and Lou (2013) considered the effects of design parameters on the slip phenomenon in a centrifugal compressor [16] and concluded that more detailed studies on the slip phenomenon were required since many questions have been left unanswered.

Moreover, the design of all elements of a centrifugal compressor and their interactions affects the flow slip [20,21]. However, to the best of the author's knowledge, no published work has been found in the literature including all these details. In this study, the slip factor in a centrifugal compressor was investigated by considering the splitter blades in the impeller and variable exit angles of the blade from hub to shroud.

\section{Definitions and formulation}

\subsection{Definition of parameters}

Experimental results showed that the flow angle at the impeller exit $\left(\beta_{2}\right)$ was always smaller than the exit angle of the blades $\left(\beta_{2}^{\prime}\right)$. In other words, the flow does not completely follow the impeller curvature, which leads to a change in the tangential component of velocity at the impeller exit $\left(\Delta C_{u 2}\right)$. Figure 1 shows

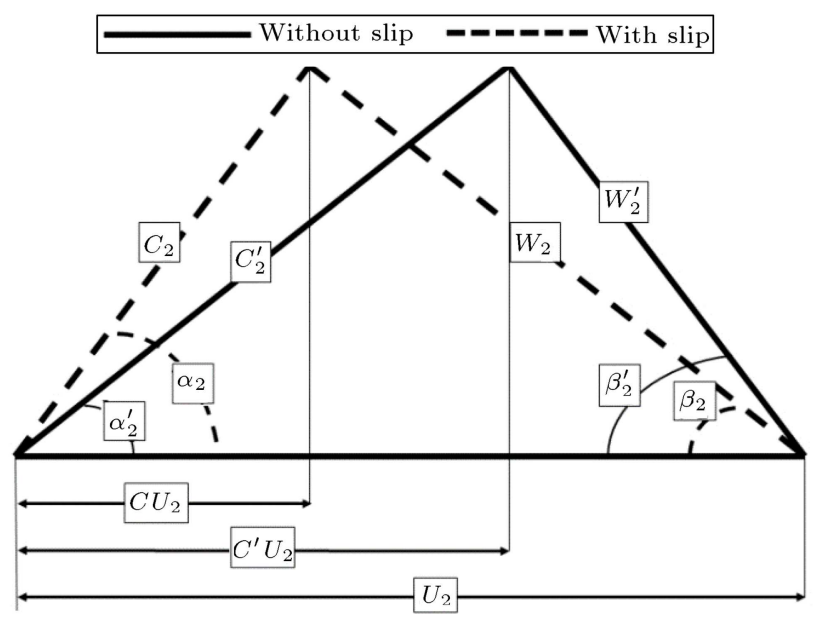

Figure 1. Velocity triangles at the exit of the impeller with and without slip. 
the velocity triangles at the impeller exit. The slip factor $(\sigma)$ is defined as follows [22]:

$$
\sigma=\frac{C_{u 2}}{C_{u 2}^{\prime}} .
$$

In this equation, the flow field is assumed two dimensional. In a real and three-dimensional flow condition, the slip factor varies from point to point; thus, it should be used as an average equation while reporting a single value, as shown in the following:

$$
\bar{\sigma}=\frac{\int \sigma d \dot{m}}{\int d \dot{m}} .
$$

The present study defines the mass parameter, isentropic efficiency, and pressure ratio as follows:

$$
\begin{aligned}
& M P=\dot{m} \frac{\sqrt{T_{t, i}}}{p_{t, i}}, \\
& P R=\frac{P_{t, o}}{P_{t, i}}, \\
& \eta=\frac{\left(\frac{P_{t, o}}{P_{t, i}}\right)^{\frac{\gamma-1}{\gamma}}-1}{\frac{T_{t, o}}{T_{t, i}}-1} .
\end{aligned}
$$

\subsection{Specifications of the compressor}

The compressor used in this research is a model 4082 turbocharger compressor manufactured by Garret company. This compressor is installed in the testbed of turbocharger laboratory at Sharif University of Technology. The compressor geometry and performance specifications are given in Table 1.

\section{Experimental method}

In this research, experimental investigations were carried out to understand the slip phenomenon better and evaluate the accuracy of numerical simulations. To this end, the setup and facilities of the Turbocharger Lab
Table 1. Geometry and specifications of the compressor in BEP (Best Efficiency Point).

\begin{tabular}{lc}
\hline \multicolumn{1}{c}{ Parameter } & Value \& unit \\
\hline Number of blades & 12 \\
(including splitter blades) & 60 degree \\
Blade angle, inlet & $30-45$ degree \\
Blade angle, exit & $56 \mathrm{~mm}$ \\
Eye tip diameter & $22 \mathrm{~mm}$ \\
Eye root diameter & $82 \mathrm{~mm}$ \\
Overall diameter of the impeller & $5.5 \mathrm{~mm}$ \\
Axial width of vaneless diffuser & $92000 \mathrm{rpm}$ \\
Rotational speed & $0.287 \mathrm{~kg} / \mathrm{s}$ \\
Mass flow & 2.17 \\
Pressure ratio & 0.85 \\
Isentropic efficiency & $41 \mathrm{~mm}$ \\
\hline
\end{tabular}

at Sharif University of Technology were employed. A schematic of this setup is shown in Figure 2. The compressor used for these experiments is a turbocharger one. In the testbed, compressed air was used to derive the turbine and compressor at the same rotational speed. It is possible to do tests at different working points of the compressor in steady-state conditions and measure physical quantities, namely static and total pressures, temperatures, mass flow rates, and rotational speed, at different stations. Therefore, the compressor characteristic curves and flow field specifications can be obtained, as shown in [23-25].

Five screw compressors were used to produce pressurized air at around 7 bar, stored in reservoirs, which would run the turbine after passing through filters and valves. The compressor was driven by this turbine and it controlled the rotational speed of the turbocharger. It also absorbed the air from the

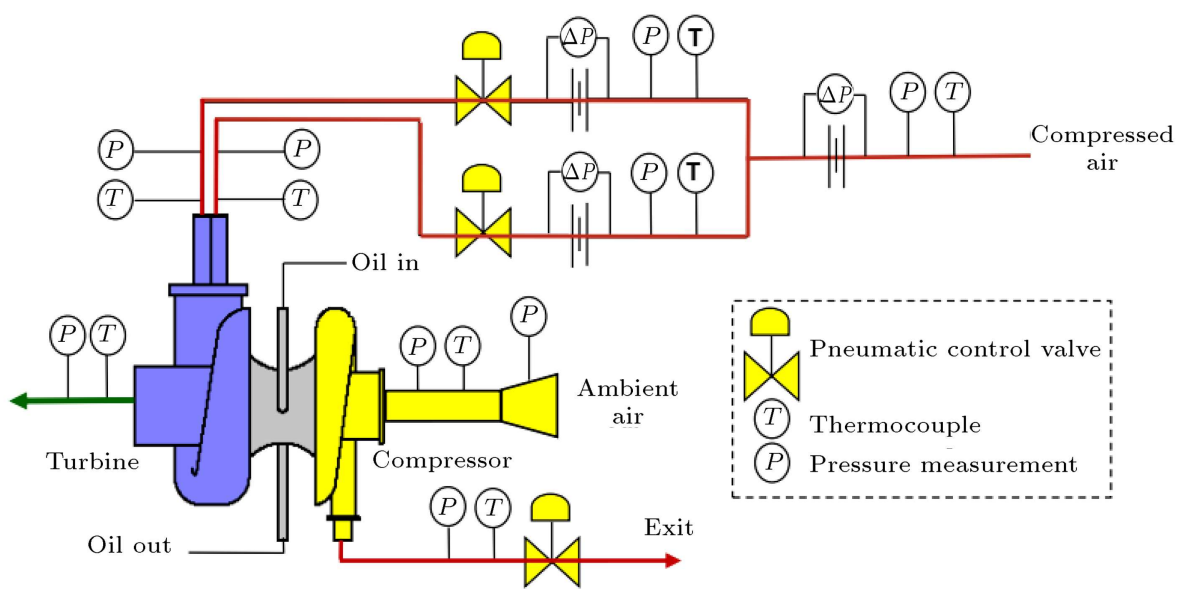

Figure 2. Schematic of turbocharger laboratory. 
ambiance through a bell mouth, used for measuring the mass flow rate. The compressor tests were performed at several speeds of 40-92 krpm with at least 5 operating points at each rotational speed and they were uniformly spaced over a range of flow rates. Every test was repeated several times to ensure repeatability. The mass flow rates of both compressor and turbine were controlled with several electro-pneumatic valves. Total pressures were sampled with pitot tubes and measured with pressure transducers at the inlet and outlet of the compressor. Total temperatures were measured by $\mathrm{J}$ type thermocouples. A fiber optic sensor was used to measure the rotational speed of the turbocharger shaft. The required data were automatically obtained using a data acquisition system, saved on a PC, and processed using suitable software packages.

Due to the errors in every experiment, identification and estimation of them are essential to specify the reliability of the results. Standards such as PTC 10 or PTC 19.1 describe correct methods for preparing the laboratory, instrumentations, and thermodynamic calculations $[26,27]$. In addition, PTC 19.2 and PTC 19.3 introduce pressure and temperature measurement in detail $[28,29]$. The main sources of uncertainty in this study are categorized into 5 groups: location, installation, calibration, device, and acquisition [30]. By combining the effects of these errors, the total uncertainty in the desired parameters was calculated [31].

\section{Simulation procedure}

A steady-state $3 \mathrm{D}$ viscous commercial solver was employed for flow field simulations. Flow domain was divided into four segments including inlet, impeller, diffuser, and volute. For each segment, grids were generated according to their particular geometry. For example, there are blades in the impeller domain and they are moving elements; thus, a dynamic grid is generated based on the blade geometry, as presented in Figure 3.

The segregated method was used for the discretization of momentum and energy equations due

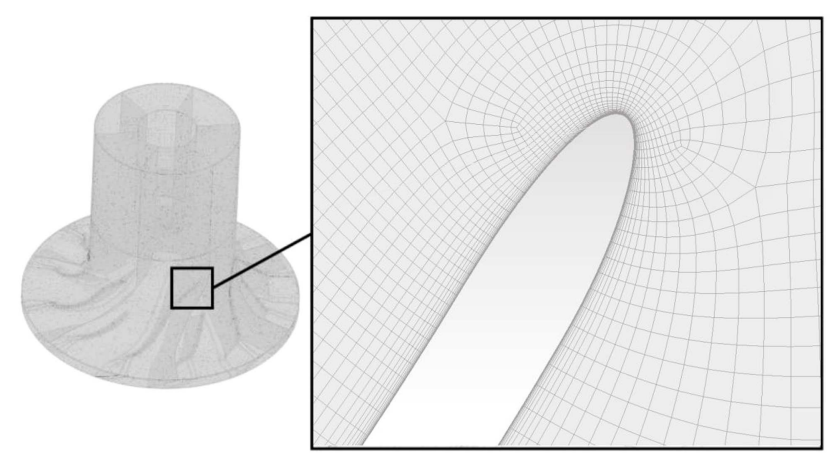

Figure 3. Details of grid in the impeller. to several advantages that it had in flow simulation of the centrifugal compressor convergence. Here, the SIMPLEC algorithm was utilized [32]. The Shear Stress Transport (SST) turbulence method was also used, benefiting from good accuracy of the $k-\omega$ method and $k-\omega$ method near the walls and outside the boundary layer, respectively $[33,34]$.

Boundary conditions of this simulation are total pressure and total temperature at the inlet of the compressor and mass flow at its outlet, as shown in Figure 4. Turbulence intensity for the inlet flow is assumed to be $5 \%$ [32]. Due to the steady state condition in this study, the frozen rotor method was utilized to facilitate the flow passage among the rotating and stationary parts of the compressor. This method enjoys a critical advantage, i.e., keeping the details of the flow.

Structured grids were taken into consideration in the inlet region and impeller. O-type and H-type grids were used for the leading and trailing edges of the blades, respectively. The grids in the volute were unstructured because of their complicated geometry, and those in the boundary layer were used for achieving higher accuracy close to the walls of the volute, as shown in Figure 5.

The present study investigated how the numerical solution was independent of the grid sizes. The appropriate number of elements was found to be approximately 3 million. The total number of grid cells was 600000 for each passage of the impeller, 130000 for the diffuser, and 2.2 million for volute.

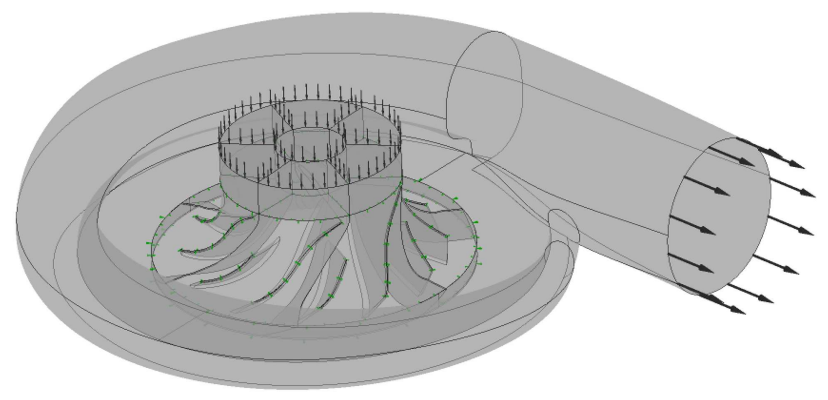

Figure 4. The computational domain.

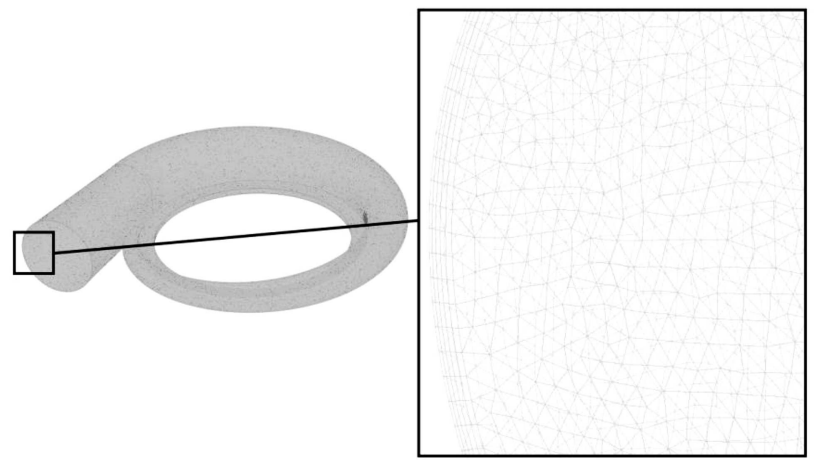

Figure 5. Details of grid in the volute. 


\subsection{Verification of simulation results}

A brief summary of streamlines in the computational domain can be seen in Figure 6. To verify the simulation results, they were compared with the experimental data in terms of pressure ratio and isentropic efficiency, as shown in Figures 7 and 8 at $70 \mathrm{krpm}$. According to the calculations, the uncertainties at Best Efficiency Point (BEP) for efficiency and pressure ratio were $1.8 \%$ and $2.0 \%$, respectively. The overall trends of curves were the same. The maximum differences between the simulation and experimental results were $2.6 \%$ in the isentropic efficiency and $1.2 \%$ in the pressure ratio.

The accuracy of the computed slip factors was evaluated using the experimental data, as described in [24].

In the experimental tests, the total and static pressures were measured at the impeller outlet through which the Mach number and velocity could be calculated as follows:

$$
\frac{P_{t}}{P_{s}}=\left(1+\frac{\gamma-1}{2} M^{2}\right)^{\frac{\gamma}{\gamma-1}} .
$$

The radial component of velocity can be calculated in any section of the compressor from the mass flow rate and cross-section area:

$$
\dot{m}=\rho A C_{r} .
$$

Through the flow velocity and radial velocity, the circumferential component is calculated in the following:

$$
C^{2}=\sqrt{C_{r}^{2}+C_{u}^{2}}
$$

Also, the slip factor can be obtained as follows:

$$
C_{u}=\sigma C_{u}^{\text {ideal }} .
$$

Since the flow field is three dimensional, a weight average function is used to define the average of parameters for the required surface. As shown in the following equation, this average is calculated based on the mass flow rate:

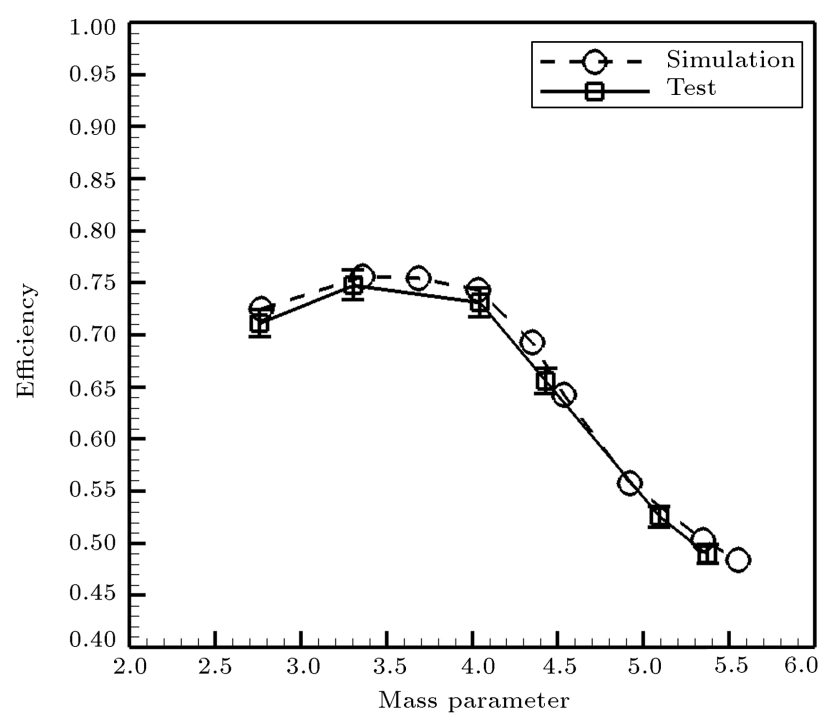

Figure 7. Comparison between computed and experimental isentropic efficiencies for different mass parameters (total to total, at $90 \mathrm{krpm}$ ).

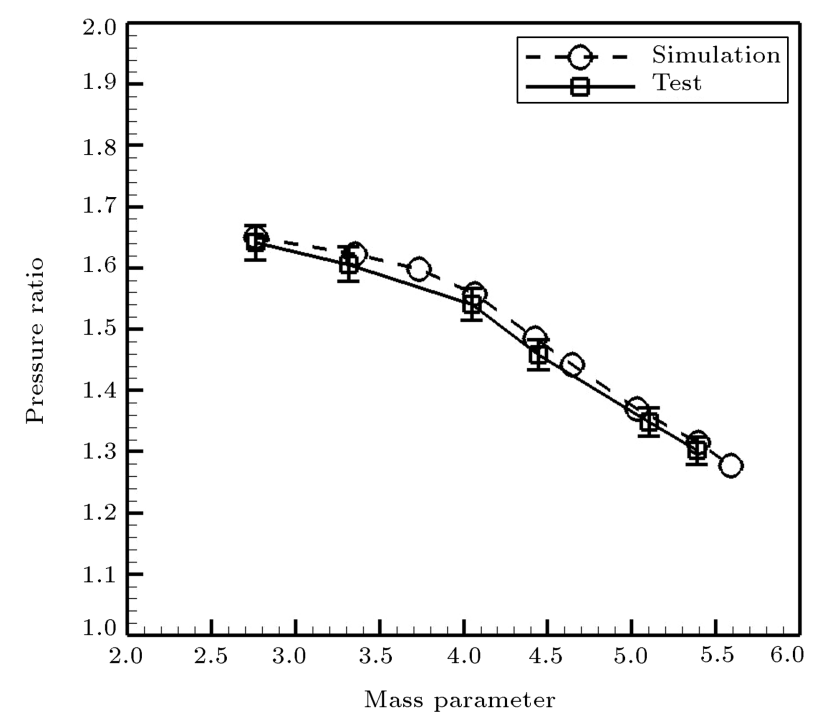

Figure 8. Comparison between computed and experimental pressure ratios at $70 \mathrm{krpm}$ for different mass parameters.
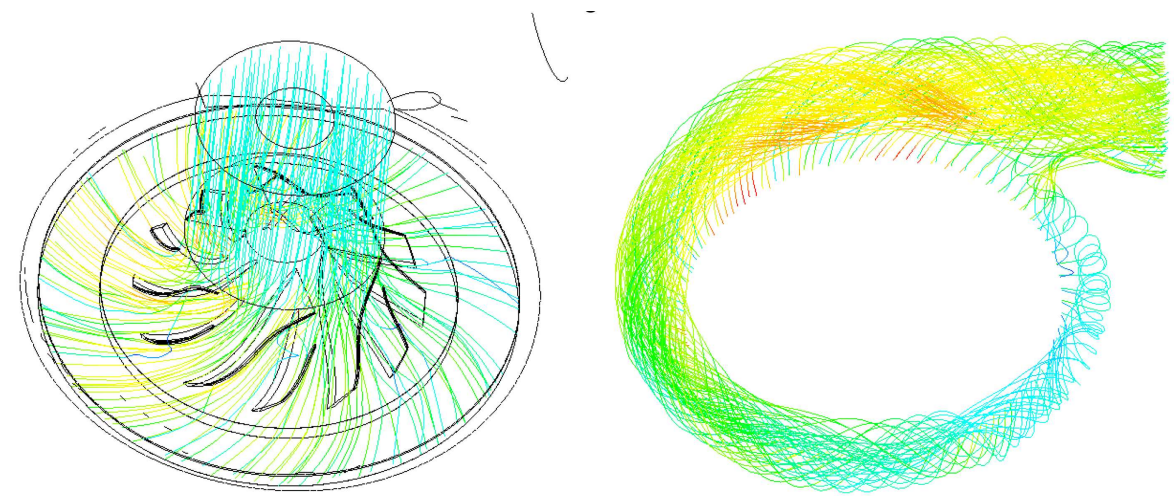

Figure 6. Streamlines in inlet, impeller and diffuser (left) and volute (right) of the simulated compressor. 


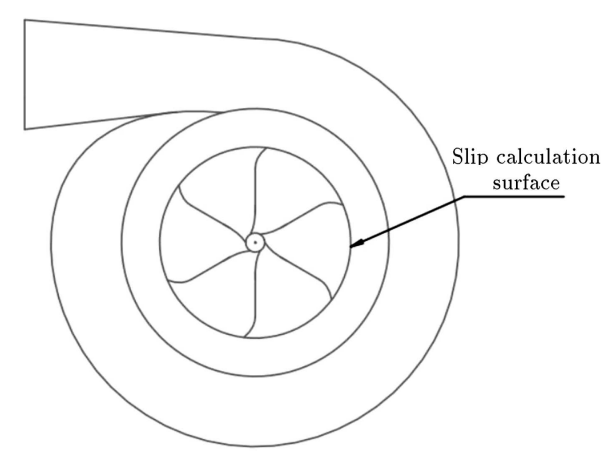

Figure 9. The surface of slip investigations.

$$
\bar{\varphi}=\frac{\int \varphi d \dot{m}}{\int d \dot{m}} \stackrel{\text { Discritization }}{\longrightarrow} \frac{\sum \varphi \dot{m}}{\sum \dot{m}} .
$$

This equation is used for the outlet of the compressor to determine total temperature and total pressure and for the exit surface of the impeller to determine circumferential and radial components of velocity. The exit surface of the impeller is shown in Figure 9.

After measuring the total temperature and total pressure at the outlet of the compressor, the efficiency and pressure ratios can be calculated using Eqs. (9) and (10), respectively. Moreover, by determining the circumferential and radial components of velocity at the exit surface of the impeller and using the rotational speed of compressor and radius of the exit surface, the slip factor and flow angle were respectively calculated:

$$
\sigma=\frac{\bar{C}_{u}}{r \omega}
$$

and:

$$
\theta=\tan ^{-1} \frac{\bar{C}_{u}}{\bar{C}_{r}} .
$$

According to Figure 10, the trends of the simulation results and experimental data are the same and the maximum difference is $3.4 \%$ at $60 \mathrm{krpm}$. Therefore, it can be concluded that the obtained accuracy of the simulation while predicting the flow field and slip factor was acceptable.

\subsection{Evaluation of the slip factor equations}

Two problems may arise while using the slip factor equations discussed in the Introduction. Firstly, most of these equations were derived for impellers without splitter blades, which is not the case in this study. Secondly, the exit angle of blades in these equations is generally regarded as a constant, while in the present study, the exit angle changes from hub to shroud. Figure 11 shows a comparison between the slip factors calculated using these equations and the experimental data obtained in this study. As observed, only Stodola and Stanitz equations yielded acceptable results, with differences of $3 \%$ and $5 \%$, respectively, near BEP of the compressor. Far from BEP, all equations would yield quite different results.

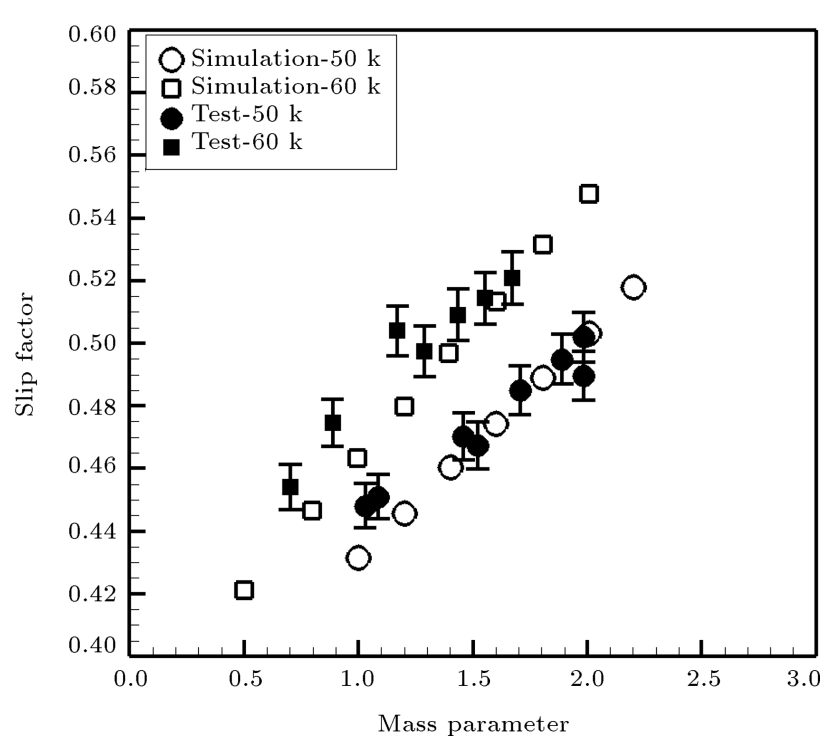

Figure 10. Comparison between computed and experimental slip factors at 50 and $60 \mathrm{krpm}$.

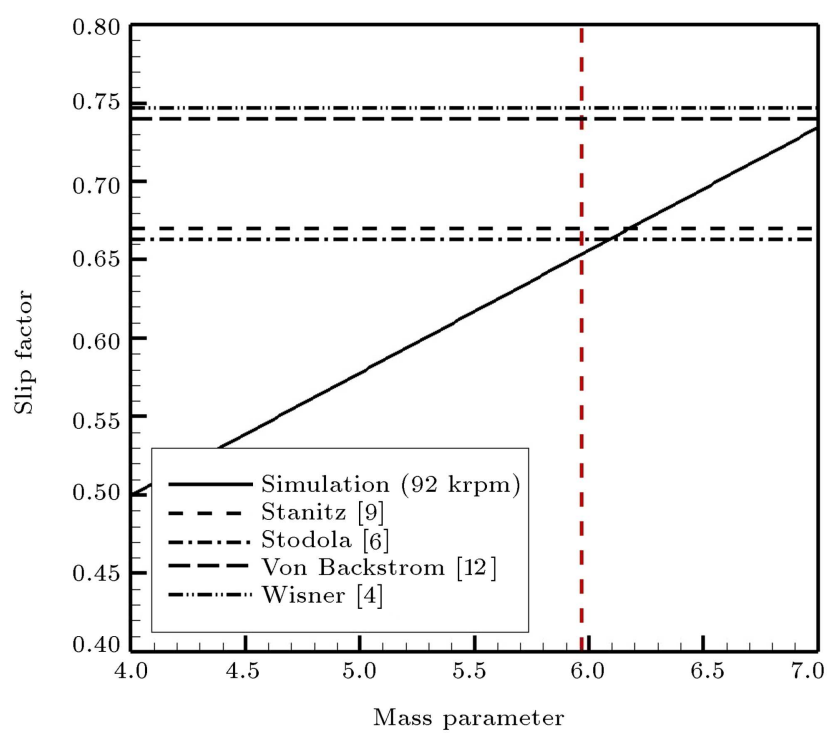

Figure 11. Comparing the slip factors obtained by the equations proposed in the literature with experimental data (red line specifies Best Efficiency Point (BEP) mass flow rate).

\section{Slip factor and design parameters}

In this section, the effects of some design parameters on the slip factor of the centrifugal compressor are investigated. At every step of this study, the slip factor and flow angle are separately determined. These parameters are calculated on the exit surface of the impeller, as presented in Figure 9.

\subsection{Effects of rotational speed and mass flow rate}

Although the effects of rotational speeds and mass flow rates on the slip factor have been studied before [11], 


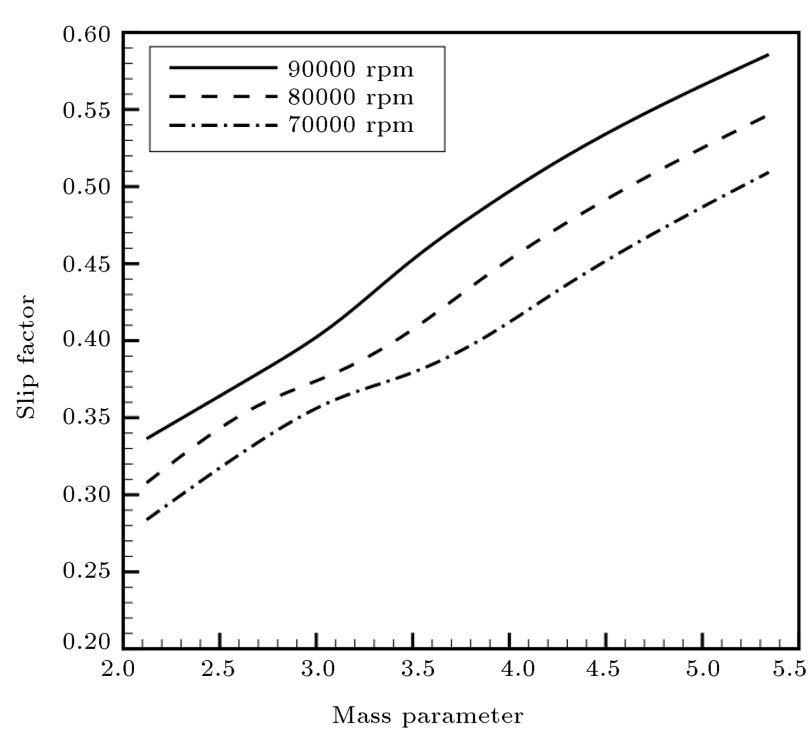

Figure 12. The slip factor variation versus mass flow at three rotational speeds.

these studies have not taken into account the profiles of splitter or complex blades. To this end, three rotational speeds in a wide range of mass flow rates are considered in this section. The slip factor and flow angle are calculated at the exit of the impeller for all conditions.

Figure 12 shows that increasing the rotational speed mass parameter would consequently increase the slip factor. This trend was already expected due to the effect of diffusion on the exit jet of the impeller [11]. Besides, increasing the mass flow rate led to a higher overall diffusion factor in the impeller and reduced the wake region. Therefore, the exit jet of the impeller fills a higher percentage of the exit area, thus increasing the slip factor. The exit angle of the impeller (from radial direction) was 30.4 degrees at the hub and 43.9 degrees at the shroud. The flow angle of the simulation results was calculated using tangential and radial components of the relative velocity (from radial direction). As shown in Figure 13, the effects of the mass flow and rotational speed on the flow angle were investigated.

Flow angle curves at three simulated rotational speeds reached their maximum amount when plotted against the mass flow rate. Accordingly, at flow rates lower than the maximum point, higher rotational speeds had higher flow angles and at flow rates higher than the maximum point, an inverse trend was observed.

\subsection{Effect of the number of impeller blades}

According to the literature, incorporating the number of blades in centrifugal compressors would increase the slip factor because the flow was severely constrained to the profile of the blades [11]. However, no source has ever demonstrated the effect of the number of splitter blades on the slip factor and the effect of profiles of the complex blade, as well.

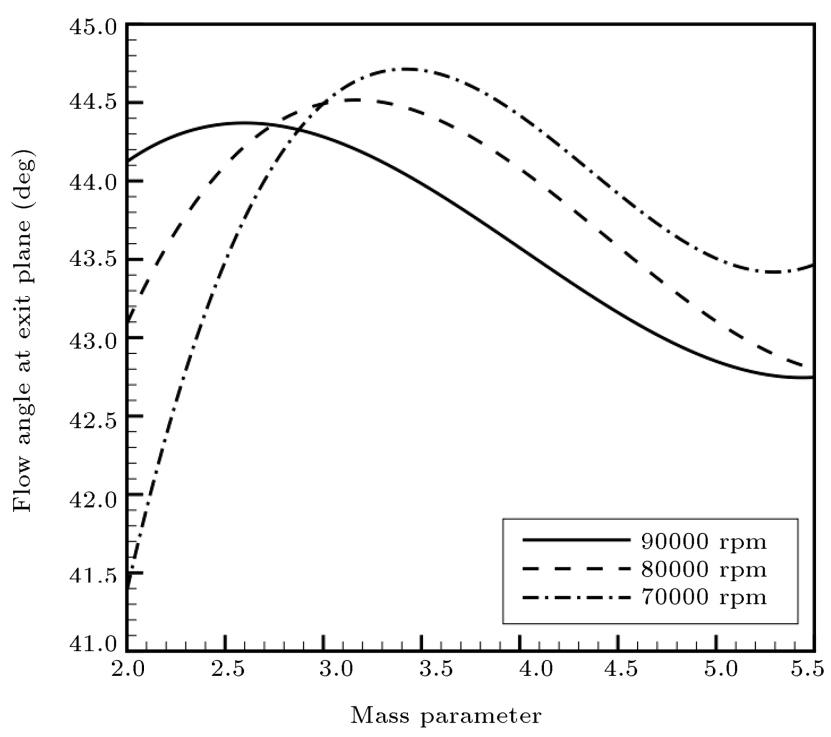

Figure 13. Variation in the flow angle with respect to the flow rate at different rotational speeds.

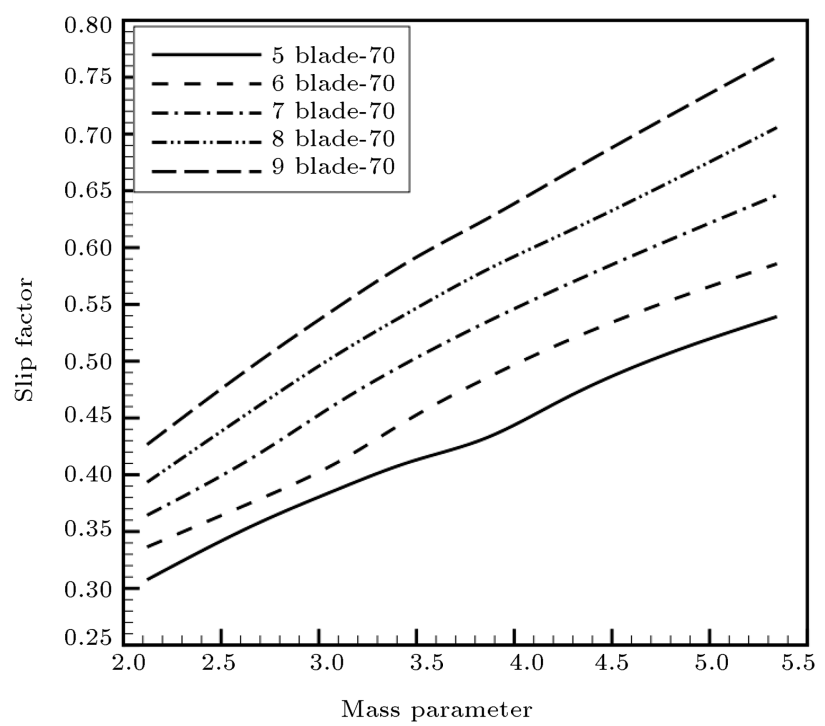

Figure 14. Variation of the slip factor with the mass flow rate for different blade numbers.

The compressor includes six blades and six splitter blades. In this investigation, the number of blades varied from 5 to 9 , keeping their profiles the same. The effect of the rotational speed was also investigated in the previous sections; therefore, in the following, only one rotational speed, i.e., $70 \mathrm{krpm}$, will be investigated. Figure 14 shows that increasing the number of blades leads to higher values for the slip factor for all mass parameters. For example, the slope of the slip factor curve of a nine-blade compressor is 1.75 times greater than that of a five-blade compressor.

In addition to the slip phenomenon, the performance characteristics of the compressor should be considered. Figures 15 and 16 indicate the effects 


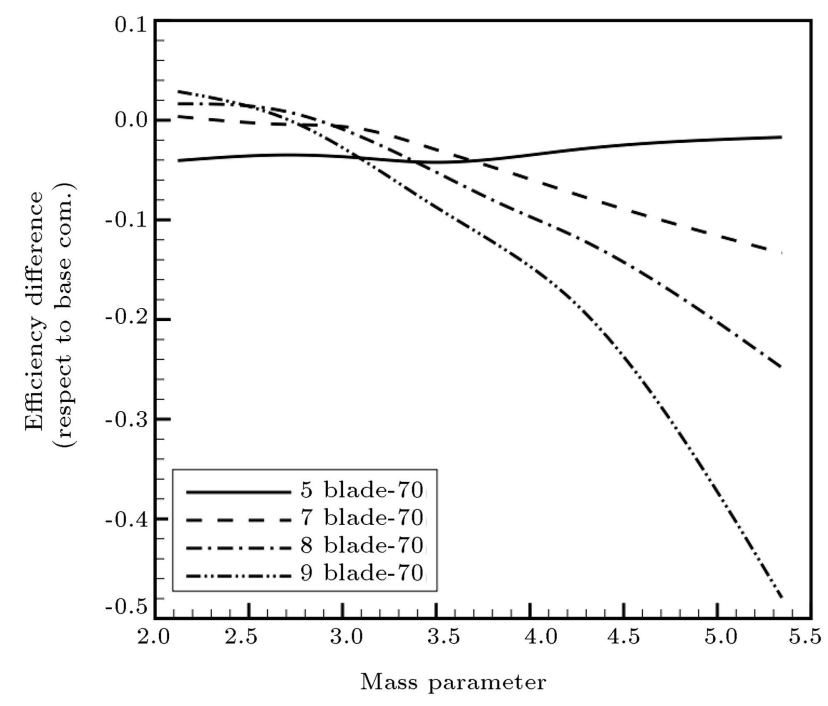

Figure 15. Variation of isentropic efficiency with the flow rate for different number of blades.

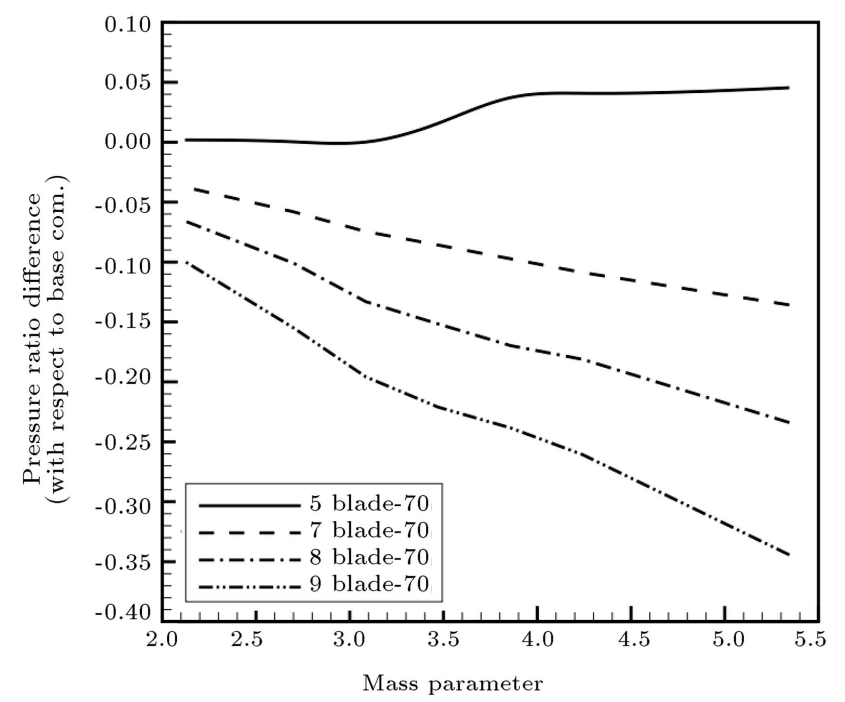

Figure 16. Variation of pressure ratio difference with the flow rate for different number of blades.

of the number of blades on the isentropic efficiency and pressure ratio, respectively. In other words, at small values of mass flow rate, the larger number of blades would increase the efficiency; however, at higher values, it led to a significant drop in efficiency. This occurs because increasing the number of blades leads to greater blockage of the flow path and this blockage becomes critical at higher flow rates because there is not enough space for flow to pass the impeller. The effect of the number of blades on the pressure ratio is similar to the efficiency.

Another comparison was made with emphasis on the effect of replacing the splitter blades by the main blades. Therefore, another design of the original compressor was investigated. The compressor used in this design has 12 main blades without any splitter.

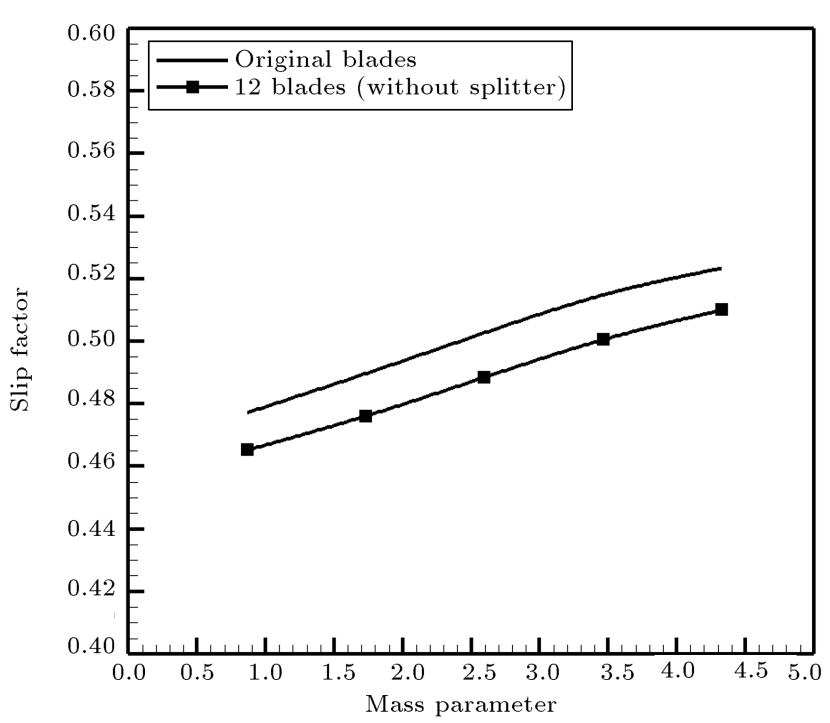

Figure 17. Variation of slip factor with the mass flow rate in cases with and without splitters.

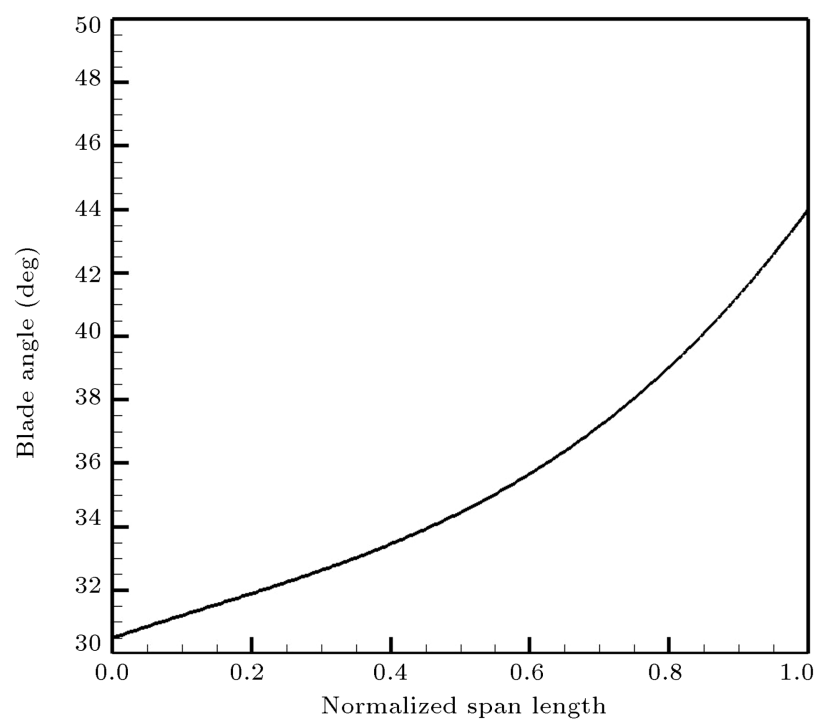

Figure 18. Variation of the blade exit angle from hub to shroud in the base design.

Figure 17 shows that at $70 \mathrm{krpm}$, the slip factor in the new impeller is lower than that in the original one. This result corresponds to the flow field in the impeller and effect of the starting point of the splitter blades [35].

\subsection{Effects of blade exit angle}

To investigate the effect of the exit angle of the blade, the blade profile was approximated by a spline function with finite control points. By changing the last control point, the exit angle varied, too; however, the overall profile remains the same. This procedure provides new blades with a smooth shape.

In the present compressor, the impeller exit angle is not constant and varies from 30 degrees at the hub to 44 degrees at the shroud, as shown in Figure 18. 


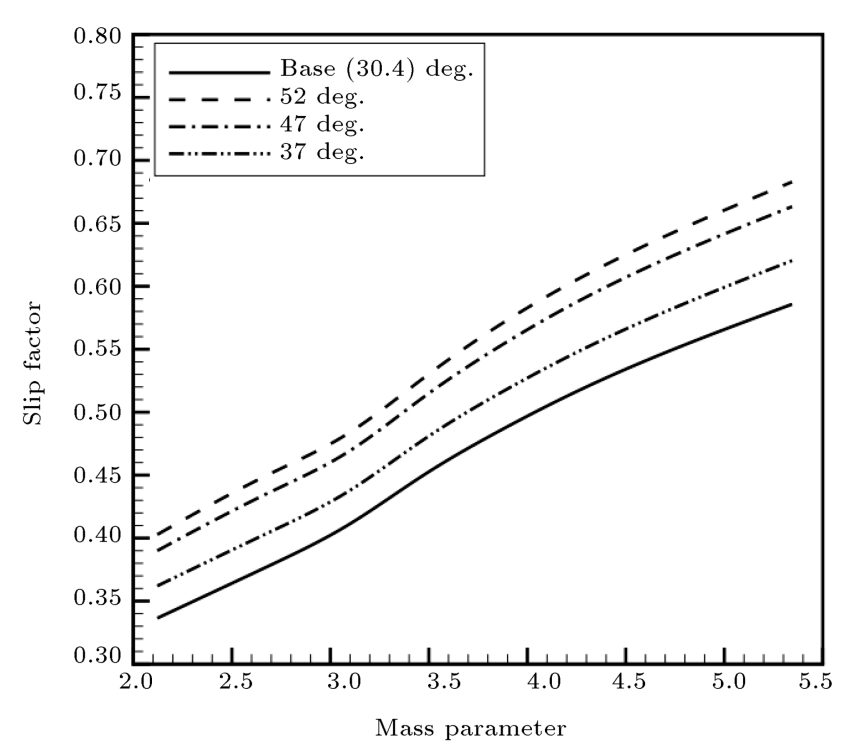

Figure 19. Variation of slip factor with the flow rate at different hub exit angles.

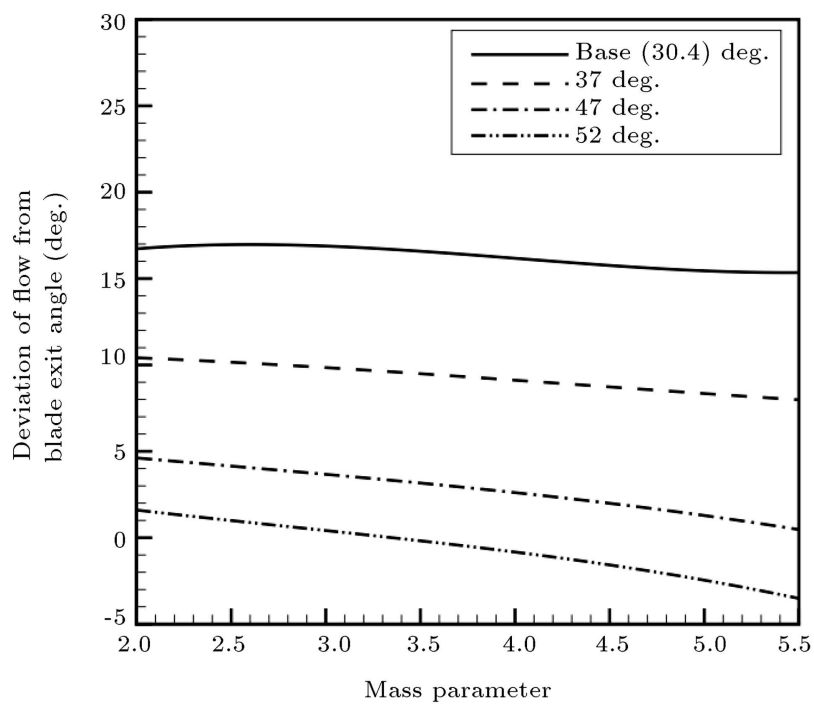

Figure 20. Variation of flow deviation with the flow rate at different exit angles at the hub.

Therefore, the study of the exit angle of the blade was performed for two separate cases:

1. Exit angle variations at hub;

2. Exit angle variations at shroud.

Figure 19 shows the computed slip factors as the exit angle varies at the hub. In other words, the higher the exit angle is, the higher the slip factor becomes. In addition, a similar trend was observed in all cases.

Figure 20 shows the effects of the variation in the exit angle of the blade at the hub on flow deviations. As observed, the higher the exit angles are, the lower the flow deviations will be.

Simulation results showed the negligible effect of

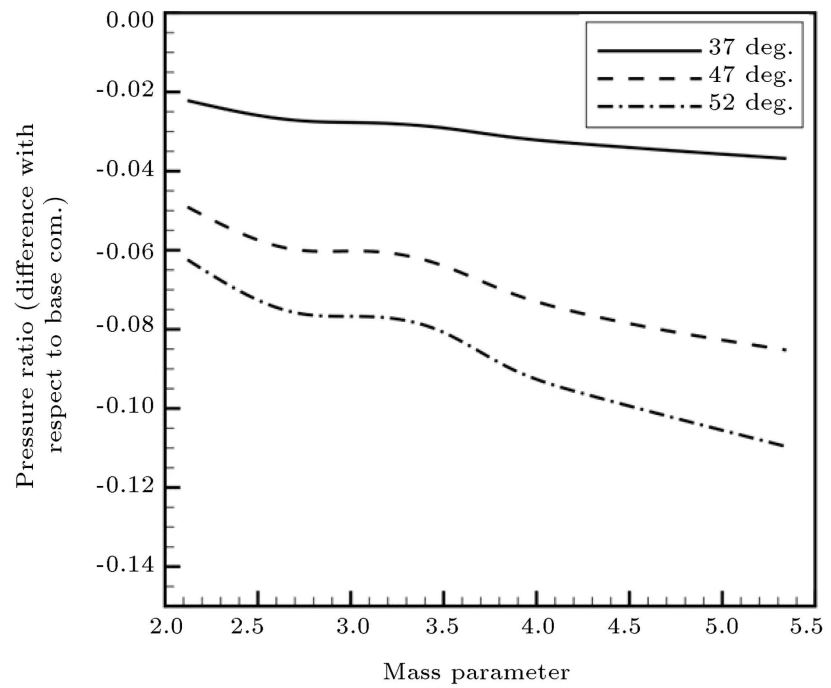

Figure 21. Variation of pressure ratio with the flow rate at different hub exit angles (at $70 \mathrm{krpm}$ ).

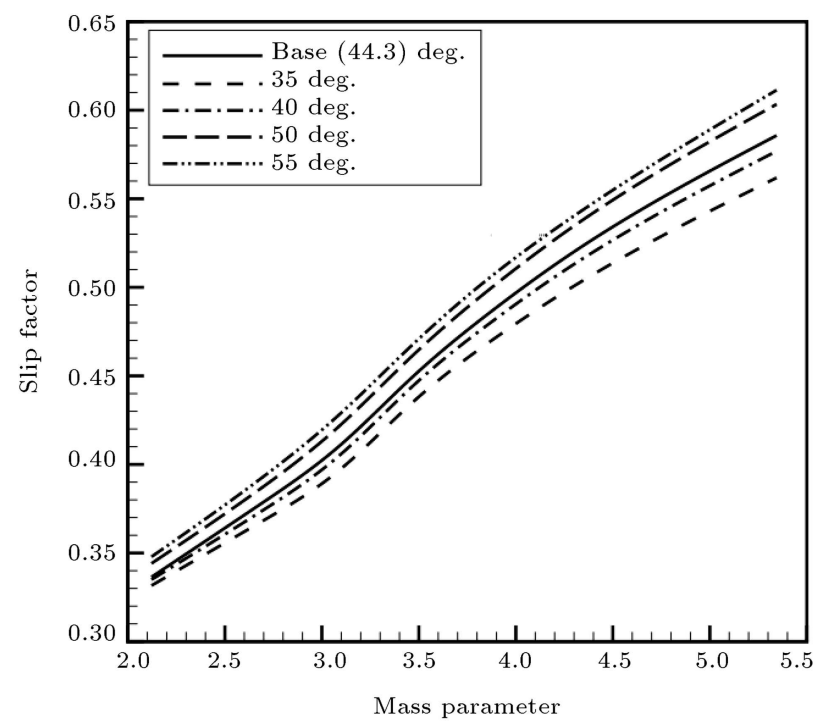

Figure 22. Variation of slip factor with the flow rate at different shroud exit angles.

this parameter on the isentropic efficiency. According to Figure 21, higher exit angles of the blade at hub lead to a greater decrease in the pressure ratio, which is intensified at higher flow rates.

A similar study was carried out by considering the exit angle of the blades at the shroud varying from 35 to 55 degrees. Figure 22 shows that higher exit angles at the shroud increase the slip factor, showing similar results to those obtained at the hub. The trend of variation in the flow angle at the shroud is also similar to that at the hub, as shown in Figure 23.

A brief review of the performance parameters of the compressor shows that the exit angle variations (hub and shroud) did not significantly change the pressure ratio and isentropic efficiency; however, at exit 


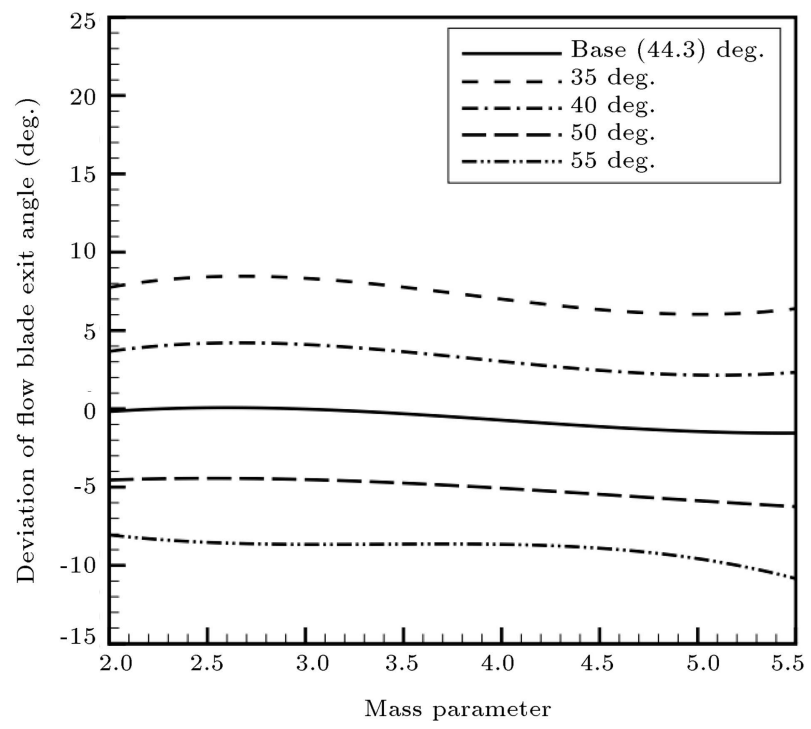

Figure 23. Variation of flow deviation with the flow rate at different shroud exit angles.

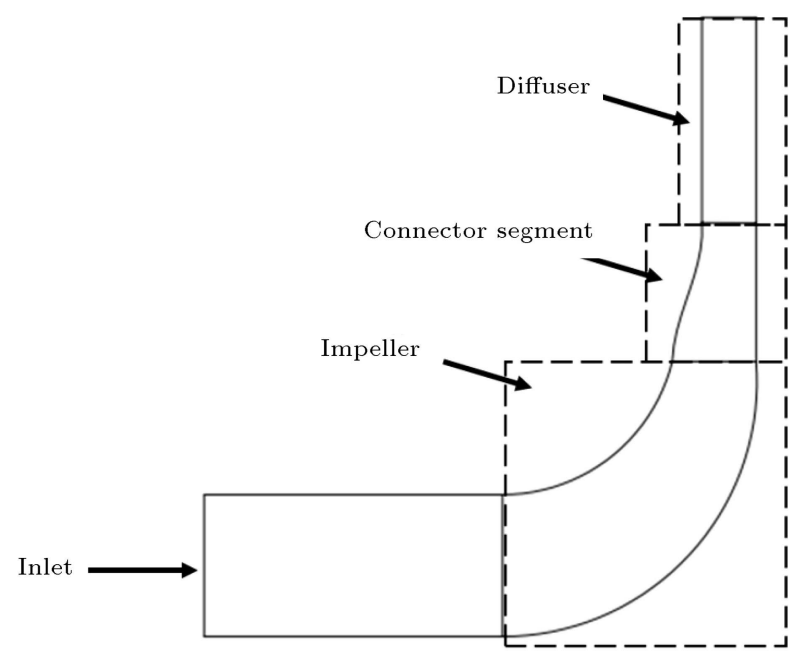

Figure 24. The schematic of the flow passage of compressor.

angles of the blade below the values of the original design, an $8 \%$ drop in the pressure ratio was observed.

Furthermore, higher exit angles increased the slip factor and decreased flow deviation, indicating that centrifugal compressors performed differently from the pumps [15].

\subsection{Effects of the diffuser design and connector segment}

To the best of our knowledge, there are not any available sources or research in the open literature on the effects of diffuser design on the slip phenomenon, and most of the investigations are limited to the impeller section. In this research, two variations of the compressor diffuser were investigated. In the first case, "D1", the diffuser width varied from 4.27 to $3.50 \mathrm{~mm}$; in the second case, "D2", the shroud profile

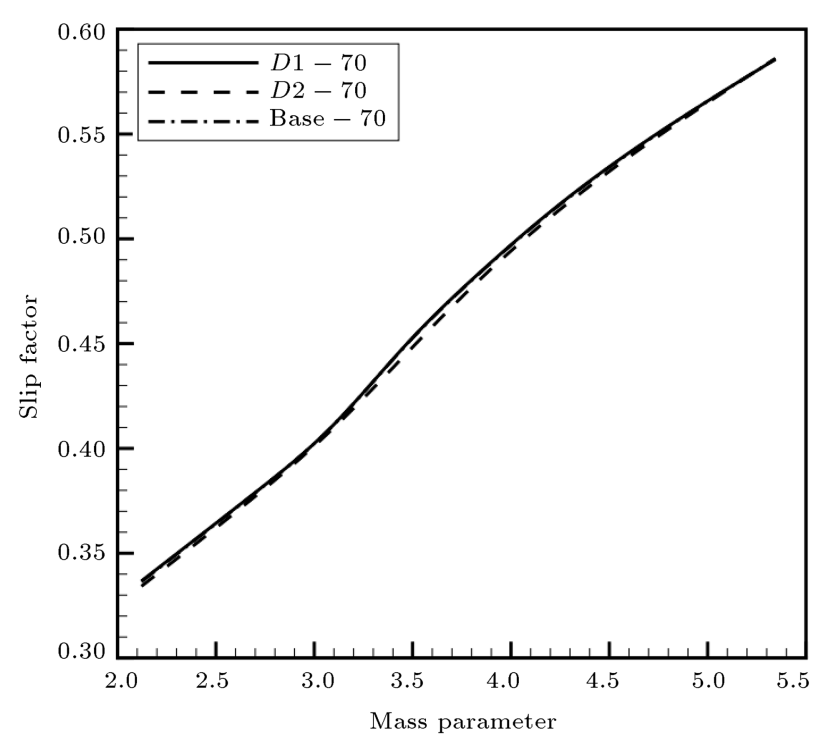

Figure 25. Variation of slip factor with the flow rate and diffuser design.

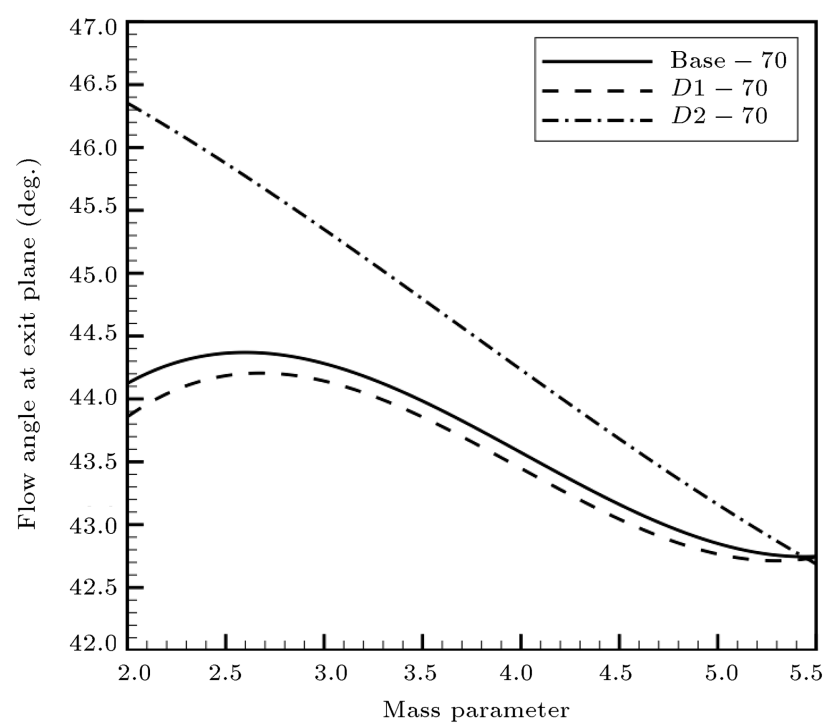

Figure 26. Variations in the flow angle with the flow angle and diffuser design.

of the connector segment was modified, see Figure 24 . The original profile of the connector segment at the shroud includes two concavities and is constrained to be tangent to the impeller outlet and diffuser inlet. The second variation is a Spline curve that fits with one concavity and is only constrained to be tangent to the diffuser inlet.

Simulation results in Figure 25 show that these variations change the slip factor slightly. In the first case, the trend of flow angle remained similar to the initial design with its value decreasing. In the second case, its trend changed slightly and the flow deviation increased, see Figure 26. Therefore, it was found that the design of the diffuser and the connector segment affected the slip phenomenon. 


\subsection{Effects of tip clearance}

In the open literature, the effects of tip clearance on the slip phenomenon remain unclear. The original compressor tip clearance is $0.4 \mathrm{~mm}$; besides, to investigate this parameter, two other values, 0.2 and $0.6 \mathrm{~mm}$, are simulated. It can be seen that the slip factor is higher when tip clearance increases, and vice versa (Figure 27). This is not expected because decrease in the tip clearance usually improves the performance parameters for centrifugal compressors [36,37].

Figure 28 shows that modifying the tip clearance does not change the trend of the flow angle and the average flow angle is inversely proportional to the value of tip clearance.

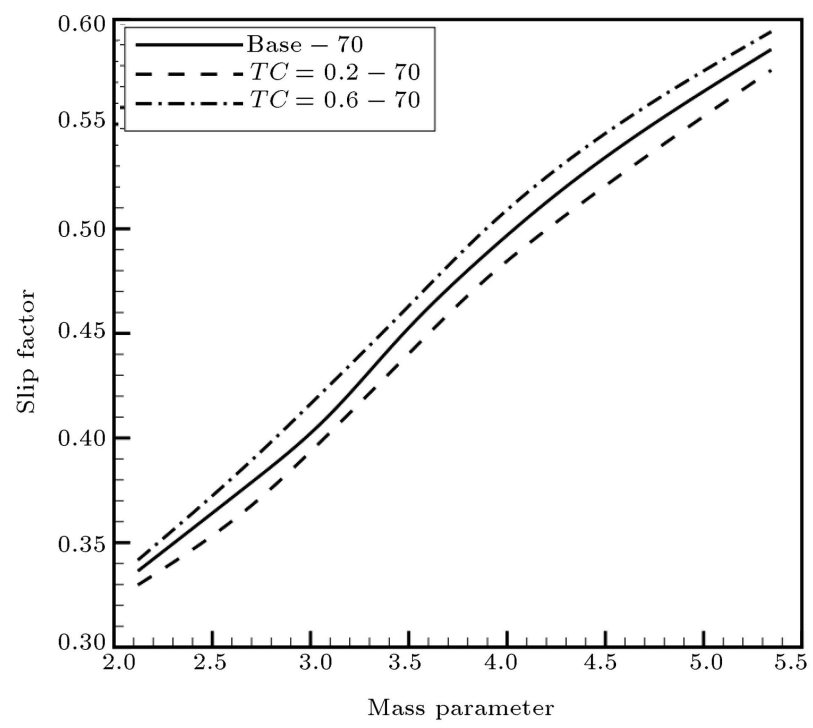

Figure 27. Variation of slip factor with the flow rate for different tip clearances.

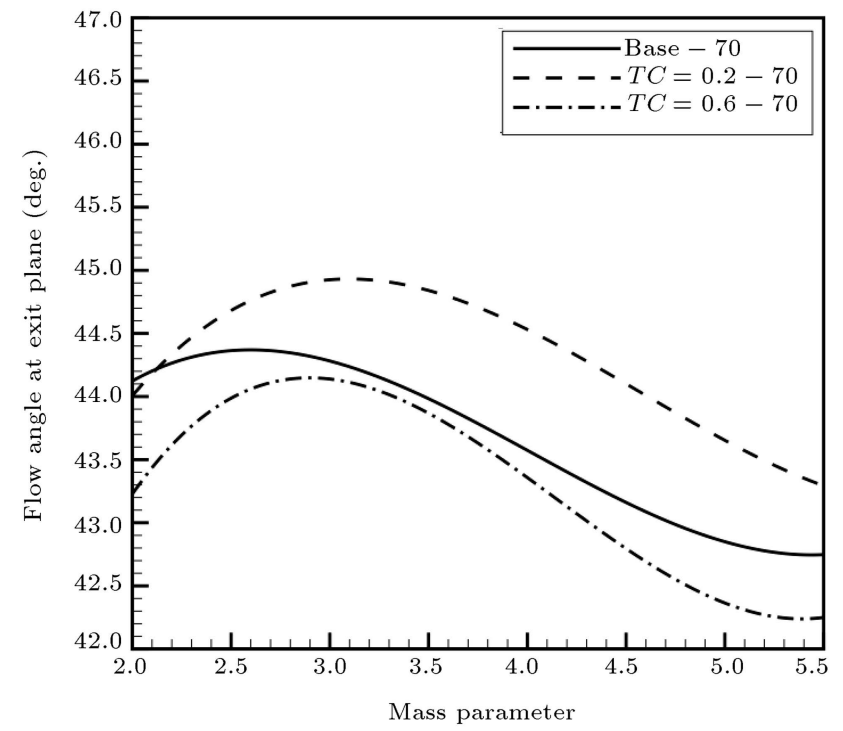

Figure 28. Variations in flow angle with the flow rate for different tip clearances.

\subsection{Effects of the lean angle}

Lean angle is one of the most important geometric parameters of a centrifugal impeller. Effect of the parameters on its performance is noticeable in axial machines [38,39]. The variation in the lean angle of the compressor employed in this study is shown in Figure 29. In this study, the lean angle varied; however, the shape of the blade profile did not vary to keep the possibility of studying the lean angle. Four different variations in the lean angle were investigated. In one design, the lean angle of the main blades of the impeller was investigated, while in another, it was studied in both main and splitters.

For the compressor studied in this work, according to Figure 30, a decrease in the lean angle leads to

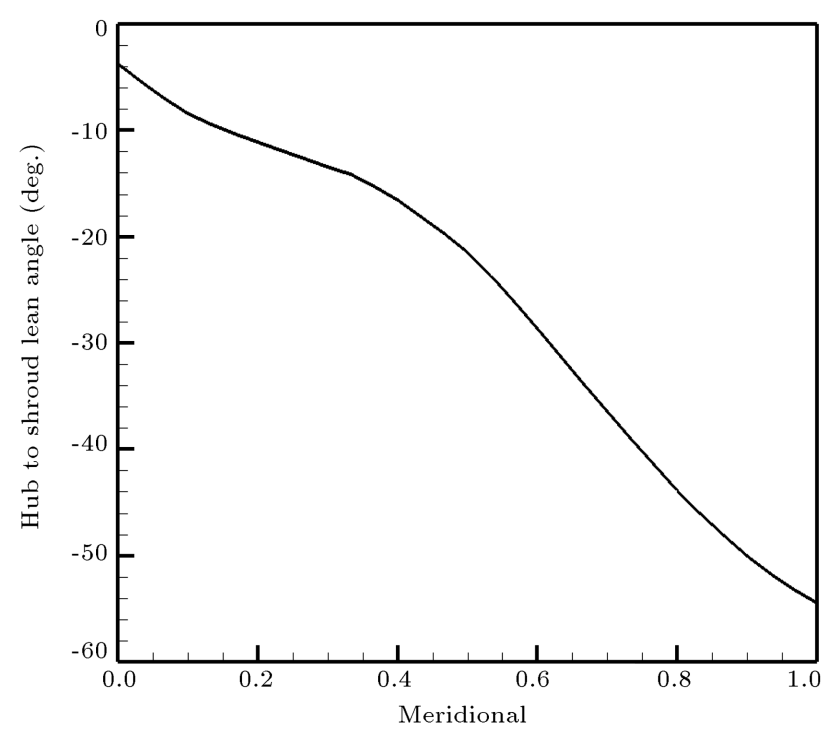

Figure 29. Hub to shroud lean angle variations (normal to mid-span).

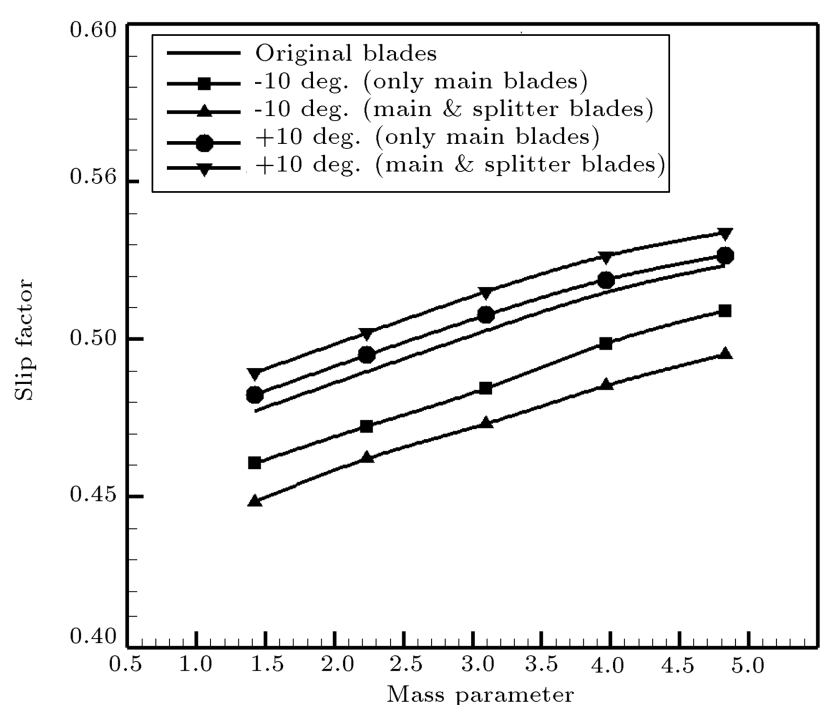

Figure 30. Variation of slip factor with the flow rate at different lean angles. 
lower slip factors, and vice versa, and also changing the lean angle of the splitter blades (favorable to the main blades) intensifies this effect.

\section{Conclusions}

The main objective of the present study was to investigate the effects of design parameters on the slip phenomenon in centrifugal compressors. To this end, one turbocharger compressor was selected on which numerical and experimental studies were performed. The slip factor, isentropic efficiency, and pressure ratio of the compressor were experimentally obtained. The maximum differences of the simulation results obtained from the experimental data were 1.2, 2.6, and 3.4\%, thus confirming the accuracy of the simulation method. The slip factor for the compressor with some of the most accepted relations was also predicted and at the Best Efficiency Point (BEP) of the original compressor, the equation developed by Stodola showed the highest accuracy with $1.5 \%$ error; however, none of them was precise enough for other working ranges.

Some of the design parameters of the centrifugal compressor were studied and the results are summarized below:

1. Increasing the rotational speed and mass flow rate of the compressor led to higher slip factors at $9 \%$, on average, for a $10 \mathrm{krpm}$ increase in speed. At a constant rotational speed, the flow angle at the exit of the impeller reached the maximum point as the mass flow rate changed;

2. Upon increasing the number of the blades of an impeller, the slip factor increased by $10-14 \%$ per each blade addition and the flow deviation at the exit of the impeller was consequently reduced. However, it caused a $0.5 \%$ decrease in the efficiency of the compressor in different mass flows;

3. Increasing the exit angle of the blades led to a higher slip factor and lower flow deviation at the exit of the impeller; however, it did not change the trend of the slip factor. On average, a ten-degree increase in this parameter led to $8 \%$ and a fivedegree increase in the slip factor and a decrease in low deviation, respectively;

4. It was shown that the width and profile of diffuser and connector segment between the impeller and diffuser slightly influenced the slip factor. Besides, these parameters affected the exit flow angle considerably;

5. Increasing the tip clearance of the compressor impeller within a limited range of $0.2 \mathrm{~mm}$ had a direct relationship with the slip factor. The difference between slip factors of the new and original compressors remained almost constant at the investigated mass flow interval;

6. Increasing the lean angle of impeller blades led to $5 \%$ higher values of the slip factor.

\section{Acknowledgement}

The authors gratefully acknowledge the support provided by the Research Office of Sharif University of Technology and the technical assistance of the Turbocharger Laboratory staff.

\begin{tabular}{ll}
\multicolumn{2}{l}{ Nomenclature } \\
$C$ & Velocity $(\mathrm{m} / \mathrm{s})$ \\
$\dot{m}$ & Mass flow rate $(\mathrm{kg} / \mathrm{s})$ \\
$P$ & Pressure $(\mathrm{Pa})$ \\
$T$ & Temperature $(\mathrm{K})$ \\
$u$ & Blade speed $(\mathrm{m} / \mathrm{s})$ \\
$Z$ & Number of blades \\
$\beta$ & Exit angle (degree) \\
$\sigma$ & Slip factor \\
$\varphi$ & Flow factor \\
Subscripts \\
2 & Exit of impeller \\
$i$ & Inlet \\
$t$ & Stagnation \\
$o$ & Outlet \\
$u$ & Tangential component \\
$r$ & Radial component
\end{tabular}

Abbreviations

BEP Best Efficiency Point

CFD Computational Fluid Dynamics

MP Mass Parameter

RR Radius Ratio (impeller inner-to-outer radius ratio)

\section{References}

1. Caridad, A.J. and Kenyery, F. "Slip factor for centrifugal impellers under single and two-phase flow conditions", Journal of Fluids Engineering, 127, pp. 317-321 (2005).

2. Whitfield, A. and Baines, N., Design of Radial Turbomachines, Harlow: Longman Scientific and Technical, pp. 83-134 (1990).

3. Ball, A.G., Bell, A.H., and Mann, L.B. "The development of the Chrysler automotive centrifugal compressor", In SAE International Congress And Exposition of Automotive Engineering (1961). 
4. Wiesner, F.J. "A review of slip factors for centrifugal impellers", Journal of Engineering for Power, 89(4), pp. 558-566 (1967).

5. Aungier, R.H., Centrifugal Compressor: A Strategy for Aerodynamics Design and Analysis, New York, ASME Press (2000).

6. Stodola, A., Steam and Gas Turbines, New York, McGraw-Hill (1927).

7. Wislicenus, F.G., Fluid Mechanics of Turbomachinery, New York, McGraw-Hill (1947).

8. Sheets, H.E. "The flow through centrifugal compressors and pumps", In Trans. Amer. Soc. Mech. Engrs, 72, p. 1009 (1950).

9. Stanitz, D.J. "Some theoretical aerodynamic investigations of impellers in radial and mixed-flow centrifugal compressors", In ASME, Cleveland, Ohio (1952).

10. Zhang, Y.L., Zhu, Z.C., Dou, H.S., Cui, B.L., Li, Y., and Xiao, J.J. "A method to determine the slip factor of centrifugal pumps through experiment", International Journal of Turbo \& Jet-Engines, 32(1), pp. 59-64 (2015).

11. Whitfield, A. "Slip factor of a centrifugal compressor and its variation with flow rate", Proceedings of the Institution of Mechanical Engineers, 188, pp. 415-421 (1974).

12. Von Backstrom, T. "A compact equation for the prediction of eddy-induced slip in centrifugal impellers", IMechE Part A: J. Power and Energy, 220(8), pp. 911-915 (2006).

13. Von Backstrom, T. "A unified correlation for slip factor in centrifugal impellers", Journal of Turbomachinery, 128(1), pp. 1-10 (2006).

14. Ji, C., Zou, J., and Fu, X. "A new correlation for slip factor in radial and mixed-flow impellers", Journal of Power and Energy, 225(1), pp. 114-119 (2010).

15. Elsheshtawy, A. "Numerical study of slip factor in centrifugal pumps and study factors affecting its performance", In International Conference on Mechanical Engineering and Material Science (2012).

16. Hung, J. and Lou, K. "Numerical investigations of slip phenomena in centrifugal compressor impellers", Turbo Jet-Engines, 30(1), pp. 123-132 (2013).

17. Xuwen, Q., Japikse, D., and Zhai, J. "Analysis and validation of a unified slip factor model for impellers at design and off-design conditions", J. Turbomach., 133(4), 041018 (Oct. 2011). https://doi.org/10.1115/1.4003022

18. Ntoko, N. "A dynamical basis for slip in centrifugal impellers", IMechE: Power and Energy, 226(5), pp. 706-711 (2012).

19. Ghaderi, M., Najafi, A., and Nourbakhsh, A. "Improving slip factor prediction for centrifugal pumps using artificial neural networks", IMechE Part A: Power and Energy, 229(4), pp. 431-438 (2015). https://doi.org/10.1177/0957650915580884
20. Plfeiderer, C.F., Die Kreiselpumpen für Flüssigkeiten und Gase, Berlin: Springer (1961).

21. Dean, C.R. "On the unresolved fluid dynamics of the centrifugal compressor", Adv Centrifugal Compressors, ASME Special Publication, pp. 1-55 (1971).

22. Van den Braembussche, R., Design and Analysis of Centrifugal Compressors, von Karman Institute, Belgium: ASME Press and John Wiley \& Sons Ltd (2019).

23. Hajilouy Benisi, A., Rad, M., and Shahhosseini, M.R. "Flow and performance characteristic of twin-entry radial turbine under full and extreme partial admission conditions", Scientia Iranica: Mechanical Engineering, 79, pp. 1127-1143 (2003).

24. Doost Mohamadi, A., Hajilouy Benisi, A., and Mojaddam, M. "Experimental \& numerical investigation of losses in centrifugal compressor components", In ASME: Turbine Technical Conference and Exposition, San Antonio, Texas (2013).

25. Mojaddam, M. and Hajilouy-Benisi, A. "Experimental and numerical flow field investigation through two types of radial flow compressor volutes", Experimental Thermal and Fluid Science, 78, pp. 137-146 (2016).

26. Performance test code for compressors and exhausters, ASME (1997).

27. Test uncertainty, ASME (2013).

28. Pressure measurement: Instruments and apparatus supplement, ASME (2010).

29. PTC 19.3 TW thermowells, ASME (2016).

30. Brun, K. and Kurz, R. "Measurement uncertainties encountered during gas turbine driven compressor field testing", Journal of Engineering for Gas Turbines and Power, 123, pp. 62-69 (2001).

31. Nakra, B.C. and Chaudhry, K.K., Instrumentation, Measurement And Analysis, New Delhi, McGraw-Hill (2003).

32. Mojaddam, M., Hajilouy Benisi, A., and Movahhedy, M. "Optimal design of the volute for a turbocharger radial flow compressor", In ASME: Turbine Technical Conference and Exposition, Düsseldorf (2014).

33. Versteeg, H. and Malalasekera, W., An Introduction to Computational Fluid Dynamics: The Finite Volume Method, 2nd Edition, Harlow, Longman Scientific \& Technical (2007).

34. Rodrigues, T.T. "Tubulence modelling evaluation for reciprocating compressor simulation", In International Compressor Engineering Conference, Purdue University (2014).

35. Moussavi, S.A., Hajilouy Benisi, A., and Durali, M. "Effect of splitter leading edge location on performance of an automotive turbocharger compressor", Energy, 123, pp. 511-520 (2017).

36. Kim, C., Lee, H., Yang, J., Son, C., and Hwang, Y. "Study on the performance of a centrifugal compressor considering running tip clearance", International Journal of Refrigeration, 65, pp. 92-102 (2016). 
37. Galindo, J., Tiseira, A., Navarro, R., and López, M.A. "Influence of tip clearance on flow behavior and noise generation of centrifugal compressors in near-surge conditions", International Journal of Heat and Fluid Flow, 52, pp. 129-139 (2015).

38. Zhang, C., Jun, H., and Zhiqiang, W. "Threedimensional compressor blading design improvements in low-speed model testing", Aerospace Science and Technology, 63, pp. 179-190 (2016).

39. Asgarshamsi A., Hajilouy Benisi A., Assempour A., and Pourfarzaneh, H. "Multi-objective optimization of lean and sweep angles for stator and rotor blades of an axial turbine", Proc IMechE Part G: J. Aerospace Engineering, 229(5), pp. 906-916 (2015).

\section{Biographies}

Shahram Rajabpour received his BS (2011) and MS degrees (2013) in Mechanical Engineering with a minor in Energy Conversion. He is currently a $\mathrm{PhD}$ Candidate at Sharif University of Technology in the field of turbomachines. His studies are focused on the experimental tests, CFD methods and simulation, and optimization and a new design method for centrifugal compressors.

Ali Hajilouy Benisi received his $\mathrm{PhD}$ degree from Mechanical Engineering Department of Imperial College at the University of London, 1993. He was a faculty member at the Institute of Water and Energy and since 1978, he has been a faculty member in the
School of Mechanical Engineering at Sharif University of Technology (SUT). He served as the Director of the Fluid Mechanics Lab (1993-1995), Founder and Director of the Turbocharger Lab (1993), Turbocharging Lab (2000), and Gas Turbine Lab (2008) in the School of Mechanical Engineering of Sharif University of Technology. His research interests are experimental and theoretical investigations of turbochargers, turbocharging, and gas turbines.

Mehrdad T. Manzari received his PhD degree from the University of Wales Swansea in 1996. He has been a Professor of Mechanical Engineering at Sharif University of Technology since 2010. He was the Director of Thermo-Fluid Group (2007-2009), Director of Center of Excellence in Energy Conversion (20072009), and Director of Graduate Studies (2005-2007) in School of Mechanical Engineering of Sharif University of Technology. He is the winner of the Most Commended Paper prize of MCB Publishers (1999 \& 2007) and Finalist of the 9th R.J. Melosh Medal Competition in USA (1997). His research interests are multiphase flows in porous media with applications in hydrocarbon reservoirs, simulation of fluid flow and heat transfer in manufacturing processes, fluid flow and heat transfer in micro-electro-mechanical-systems, non-Newtonian fluid flows, computational methods in engineering, smoothed particle hydrodynamics with engineering applications, high performance, and parallel computing. 